\title{
THE CORRELATION BETWEEN MIGRATION CHAOS, NATIONAL SECURITY AND THE COVID-19 PANDEMIC
}

DOI: https://doi.org/10.18509/GBP210395i

UDC: 314.15]:616.98:578.834\}-036.21(4-672EU)

355.45]:616.98:578.834\}-036.21(4-672EU)

\section{Metodi Ivanov}

Sofia University „St. Kliment Ohridski“, Faculty of Geology and Geography, Department "Regional Development", Sofia, Bulgaria

\begin{abstract}
The correlation between migration chaos, national security and the COVID-19 pandemic is particularly relevant given the huge waves of migration to European Union countries before the pandemic, the reverse migration during the pandemic and the national security protection of European countries, at the same time in the ability to control migration flows and assimilate the core values of the host countries, as migration exchange is a generator of terrorist or criminal transnational threats. Especially in the last few years, when Europe was flooded by giant waves of immigrants, which on the one hand created a serious problem in clarifying their identity and origin, and on the other hand caused significant changes in the socio-economic life of EU member states. This has led to the emergence and consideration of a number of issues related to the adoption of emergency measures for the distribution, accommodation and administration of migration and refugee flows by the central executive authorities of the Member States of the European Union. On the other hand, it provoked the formation of a policy focused on medium- and long-term conceptual planning and restructuring of public attitudes, applied concepts, developed strategies and implemented specific measures to address mass migration movements by creating opportunities for integration and inclusion of immigrants in social the economic and social life of the host country. While in 2020, as a result of the pandemic of COVID19 , there was a wave of reverse migration, which in turn caused social and economic consequences and problems in the individual administrative-territorial units of a number of countries, including the Republic of Bulgaria. This process has necessitated the study of local communities, as well as the planning and implementation of various mechanisms to address the problems that arose during the pandemic. The process of integration of immigrants has different dimensions, which are related on the one hand to their inclusion in the community, and on the other hand to their employment. This report will pay attention to the reverse migration on the territory of the Republic of Bulgaria and will pay significant attention to certain economic and social features in the formation and planning of policies and measures to address the pandemic of COVID-19 and the protection of national security of the country in the context of the economic and demographic aspect.
\end{abstract}

Keywords: demography, migration processes, national security, economic security

\section{INTRODUCTION}

One of the possible reasons for the decrease in the number of emigrants is the spread of the COVID-19 pandemic, as according to the European Border and Coast Guard Agency (FRONTEX) the number of people illegally crossing the borders of the European Union in 2020 fell by $13 \%$, which represents about 124,000 people entering the territory of the 
European Union. It should be noted that these are the lowest values in the last seven years, i.e. from 2013 until now. Many experts suggest that the reasons for this decline are related to the spread of COVID-19 and the introduction of restrictions on the movement of the population in all affected countries in 2020. Although the relative number of migrants has decreased, the movement is mainly along established routes through West Africa, the Central Mediterranean and the Western Balkans, mainly migrant Syrians, Tunisians, Algerians and Moroccans. A huge decrease is observed along the migration corridor in the Eastern Mediterranean through Greece, where their number has decreased by more than $75 \%$ to about 20,000 , which in fact affects the potential migratory pressure established on the Republic of Bulgaria. The most attractive migration route in 2020 of illegal immigrants from the Central Mediterranean, with the number of migrants exceeding 35,000 in 2020, while the number of illegal migrants on the route through the Western Balkans is about 27,000, on which route there is also an increase in migratory pressure in 2020 compared to the relative number of migrants in 2019.

In recent years, there has certainly been an unprecedented increase in the number of migrants and refugees wishing to enter the European Union. In the area of border control, the responsibility lies entirely with the countries holding the external border. Of course, FRONTEX has the potential to provide additional technical assistance to European Union member states facing strong migratory pressures, which are assisted by coordination in the deployment of additional technical equipment, as well as support for border protection activities through the secondment of specially trained border guards. The question remains whether and to what extent the opportunities for not only coordination of maritime operations should be increased, but also the increase of the degree of active participation in operations at the external land borders on the routes passing through the territory of the Republic of Bulgaria, i.e. whether it is necessary to move to the creation of mechanisms and opportunities for active participation in specialized operations, and not mainly FRONTEX to coordinate the creation of specialized networks for the protection of the external borders of the European Union.

All activities planned and carried out by FRONTEX are based on a risk analysis, assessing the possible risks to the security of the European Union's borders, by developing models and trends in illegal migration and cross-border criminal activity at the external borders. Coordination in the deployment of specially trained staff and technical equipment where a Member State of the European Union is under strong pressure at the external border is one of the main activities of the organization. In this context, the activity of the agency involves the implementation of a number of studies bringing together various experts related to border control, the involvement of researchers and industry related to the production of alarm and security equipment for border protection in order to seek opportunities for implementation of the new technologies in the implementation of the daily activities of the border control authorities.

All activities of the agency involve not only the development of common standards for training of bodies guarding the external borders of the European Union, but also involve a number of efforts to harmonize the training of border guards of member states, which will increase efficiency during planning and the implementation of joint operations coordinated by FRONTEX.

All these activities can assist individual organizational structures and units in developing good practices applied in the field of border control and related to the decision-making process for the return of a certain number of migrants who have entered the borders of the Member States of the European Union. In the information 21st century, where the 
importance of the development, implementation and management of information systems related to the synthesis, analysis and exchange of information between stakeholders is essential in the implementation of border control and the creation of mechanisms to overcome the consequences of implementation of the direct migratory pressure on the external borders of the member states of the European Union. Given the ever-increasing migratory pressures at the European Union's external borders, the issue of restructuring FRONTEX and creating and maintaining its own equipment and / or well-trained border guards, which can be involved at any time except on the agenda, may be on the agenda the coordination of a joint operation of the agency, as well as with direct participation in the implementation of the planned activities.

The debate on the very restructuring of FRONTEX in terms of the degree of participation in the various areas of the Agency's activity must be the subject of a wide-ranging discussion, both at European level in the face of the European Commission and the European Parliament and at a purely expert level. Member States of the European Union in the planning, development and sharing of good practices between the border authorities of the countries, as the control of the external borders of the European Union is essential in the implementation of cooperation for all Member States to improve quality at work and increasing the level of readiness to react to unusual pressure at a border of a member state of the European Union.

\section{The relationship between migratory chaos, national security and the pandemic resulting from the spread of COVID-19}

Representing the relationship between regional development, migration processes and national security is a legal, political and practical issue, as on the one hand migration processes are the result of forced and / or voluntary movements of the population in search of a dignified life in another nation state. In general, migratory movements of the population can be perceived and presented as a major pillar of the development of individual host regions, where local and national institutions are actively involved in the implementation of policies related to achieving regional integration and development through the creation of regional free movement systems that are linked to human mobility on a global scale.

It is the relationship between migration and the development of countries and regions in particular that has become central to contemporary political, economic and social debates in individual countries and at the European Union level in general. Migration processes contribute to the overall human development of both migrants and members of their countries of residence, which requires us to recognize that the migration processes themselves, regardless of the driving forces, are an opportunity for host societies to build a better and more prosperous, a global "common world" where everyone can contribute to the development of society by having the opportunity to live with dignity.

It should not be forgotten that migration processes are often a highly politicized issue, which is directly related on the one hand to national security and on the other to the preservation and preservation of national identity, and at the same time has a strong impact on economic opportunities to growth and / or decline, as the quantity and quality of migrants must be assessed through the opportunities for a highly productive workforce that has a direct impact on the economic growth of the region concerned or to create an opportunity for its decline. Conditionally, three different groups of migrants can be identified, according to the specific way in which they develop, namely the group of small and well-integrated and self-integrating immigration, the second group belongs to the 
numerous and selflessly supporting emigration, which is typical for some ethnic groups and communities where patriarchy is strongly present in the family and society and the third group are a small number of refugees, whose integration is carried out through local and national institutions and non-governmental organizations.

\section{Features of migration processes, national security and the spread of COVID-19.}

Migrations have played a very important role in the development of Mankind. „Their main function has always been to ensure people's mobility and effective territorial disposition in terms of their ability to live and work. Migrations have also contributed to the rational use of labor, human and natural resources in a given territory. Migrations are often associated with improving the educational and qualification structure of the population, increasing its cultural level, but also with the increase in its needs and the expansion of the domestic and foreign markets.

On the other hand, migrations also have contradictory consequences - loss of working time, loss of leisure time, reduction of population and deterioration of its structure, excessive concentration of population, "forced" urbanization and a number of others". [1] ,The study of the migration processes in Bulgaria has many aspects:

- Economic - labor, labor market, distribution of productive forces, human resources, labor resources, change of environment, urbanization, etc. ;

- Social - wealth and poverty, democratic values, ethnic conflicts, religious and cultural tolerance, hunger, illness, education, refugee problems, etc.;

- Demographic - population development, birth rate, growth, density, ethnic structure, religious dignity, etc.;

- Geographic - natural disasters, ecosystems, settlement or depopulation of territories, belonging to a group (ethnic or racial), etc.;

- Legal - observance and protection of human rights, protection of the child, and so on".[2]

Migration has a significant impact on the demographic development of the country in the territorial aspect and leads to a concentration of the population in the cities and urban areas around the big cities. Migration has had a significant impact on the development of the settlement network in the second half of the 20th century and the first decade of the 21 st century. It has led to a rapid decline in the number of villages and their population, deterioration in reproductive capacity, aging and increasing its negative natural growth. This century is marked by the destruction of the balance between security, society and nature, which creates conditions for fierce regional conflicts, economic crises, thousands of deaths and yet more deaths on the road of migration [3].

The demographic crisis with its multifaceted manifestations is one of the most serious problems faced by the country over the coming decades as it continues to diminish and aging population, on the one hand, due to the delayed reforms of policies to support family values, The birth rate and the retention of young people, on the other hand, given the socio-economic conditions in the country, population displacement continues beyond its borders [4]. While preserving a demographic trend, Bulgaria will continue to fall into the "demographic hole" and go towards its "demographic and economic meltdown." Within a few decades, Bulgaria has become the fourth country in the aging world after Japan, Germany and Italy.

The country is aging rapidly and, according to the UN's demographic forecasts, it will experience the sharpest drop in the world-wide working-age population. Until 2050, labor resources (population aged 15-64) will decrease by 40\%. An ever-smaller 
number of workers will generate national income for the entire population. Since the relative share of the workforce is a key factor in the level of income in the country, this decline is likely to slow down growth. The most effective way to stop further shrinking labor is to stop migration. It will be important to boost immigration. A proactive immigration policy tailored to the needs of the Bulgarian business will have to be set up [5].

The impact of demographic processes on sustainable social and economic development can be traced in the following main directions:

- In the reproduction of labor resources - number, age, gender, education;

- In the case of employment, taking into account the different employment intensity by gender and age, as well as depending on the number of children in the family, the intergenerational interval, the gender structure, the educational and professional structure of emigrants and immigrants;

- In the case of unemployment, taking into account the unemployment rate by gender, age groups, young people and persons in retirement age;

- Taking into account the level of income depending on gender and age;

- Reallocation of income depending on the size and composition of the family;

- In the formation of the poverty level. Increasing or decreasing the number of children in small and, respectively, large families affect the increase or decrease of the poverty rate of different ethnic groups;

- Demand - the growth of the population leads to an increase in demand and the relative growth of children influences the demand for children's goods. Changes in population size, marriage and divorce, have led to a change in demand for housing (by squares and by number of rooms);

- Educational services. Growing or decreasing fertility rates over a period of time leads to a 1 or 3-year increase or decrease in demand for childcare facilities, 6 or 7 years of basic education, 13 or 14 years of secondary education, and 18 or 19 Years of demand for higher education;

- Healthcare. The change in the number of the population also changes the burden on health care establishments and the sex-age structure, the birth rate and mortality rate, and the proportion of doctors in the specialties, children's polyclinics, maternity hospitals, and so on;

- Social support, child-raising and child-raising allowances, development of the social service provision network of the population As long as there is a close interaction between population reproduction and the regional socio-economic development of the country or its regions, permanent monitoring is an important tool for managing the country's sustainable socio-economic and demographic development [6].

From the presented data in the following image we can see the emerging trend of population decline in the period 2016-2020, which is due to both the negative natural increase and migration processes. 


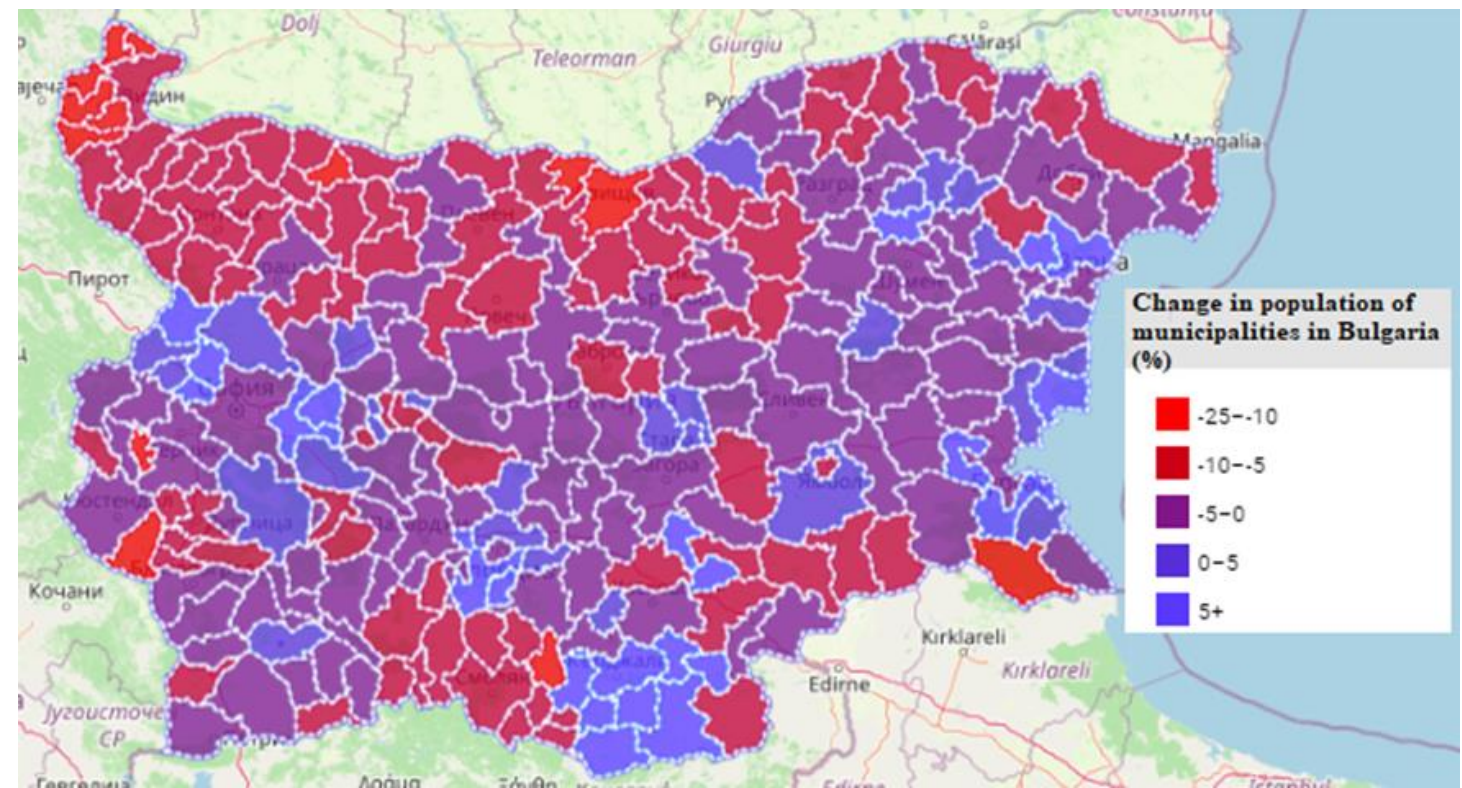

Figure 1. Population changes on municipalities in 2016-2020 [15]

During the considered five-year period in the municipalities in the Republic of Bulgaria there are tendencies of decrease of the share of the population during the considered fiveyear period, where in 214 out of 265 municipalities the population decreases. However, in 110 municipalities the decline exceeded $5 \%$ over the five-year period. Looking at the image, it can be seen that this sharp decline in population is concentrated in the municipalities located in northwestern Bulgaria and municipalities around the river Danube. This process is on the one hand the result of the lowest natural growth and aging population on the municipalities in the region, and on the other hand is a function of migration processes, which are the result of weak economic indicators in regions, very low investments and high unemployment [7]. But ,the labor market in our country is catching up due to the growing mismatch in the skills and capabilities of the workforce and the needs of the economy. And while there are policies that partly attempt to change, the problem of quality of workforce is escalating but not adequately addressed, economists and financiers say [8]".

\section{CONCLUSION}

The dynamics in the global economy predetermines the creation of new configurations of interests, as a result of which co-operation is often transformed into even confrontation, through economic, social, currency diplomatic and other sanctions, and vice versa. Certainly the choice of economic strategy to ensure regional economic security has to be determined by the duration of the impact of the destabilizing factors, the level of competitiveness of the regional economy and its degree of dependence on direct state intervention through subsidies. In essence, achieving regional economic security is not only an economic but also a political issue that is directly dependent on the situational analysis of the internal and external environment. Although in the context of globalization of national economies, regional economic security can hardly be achieved, which implies increasing demand for opportunities to implement measures at national and national level to ensure regional economic security. At the top of the international level, to guarantee regional economic security, the establishment of a system of international economic security, which also has certain features 
related to the opposite economic interests of individual countries, can be established. Certainly the choice of economic strategy to ensure regional economic security has to be determined by the duration of the impact of the destabilizing factors, the level of competitiveness of the regional economy and its degree of dependence on direct state intervention through subsidies. In essence, achieving regional economic security is not only an economic but also a political issue that is directly dependent on the situational analysis of the internal and external environment. Although in the context of globalization of national economies, regional economic security can hardly be achieved, which implies increasing demand for opportunities to implement measures at national and national level to ensure regional economic security.

At the top of the international level, to guarantee regional economic security, the establishment of a system of international economic security, which also has certain features related to the opposite economic interests of individual countries, can be established. The achievement of economic security as a whole must be related to building it at different levels, in different areas of socio-economic life, as well as to different territorial units that are in a certain dependence and subordination. This is the main reason why it is necessary to decompose the subject in economic security and to move from the particular country to analyzing and assessing economic security in the particular region. Naturally, economic security as a subject can guarantee the sustainability and development of the national economy and defend national economic interests internationally. While regional economic security as an entity can guarantee the sustainability and development of the local economy and assert local economic interests at national level as well as at international level under certain conditions.[9] „The economic impact of the pandemic will unfold over a longer time frame than many recognize at the time of writing. Comparisons with the global financial crisis may go some way to convey the seriousness of the pandemic, but that crisis will undoubtedly pale in comparison. It is clear that a significant proportion of active businesses will fail, but this failure has - in many countries - been delayed by government policies and subsidies. The conditions shaping resilience during and after the financial crisis were similar in many ways to the factors seen as driving regional growth and competitiveness in ordinary times. The current crisis, however, will undoubtedly result in some long-standing changes in the ways people and firms move and operate.

This could mean that factors which were clear advantages in the past (such as agglomeration and the possibility of unplanned interactions) might operate differently in the context and aftermath of Covid-19“"[10]. We can expect, that in 2030, global, regional and national inequalities in the political and economic spheres will generate crisis in countries across the Eastern Europe region, and maybe in all European countries. "Migration to the EU will increases. Economic and political crises, as well as environmental and natural disasters, will lead to migrant and refugee flows within the region and occasionally escalate into irregular migration flows towards the EU. African countries seek partnerships with the EU (mostly bilateral in order to address national challenges), but the expansion of informal movements and economies render many such partnerships ineffective"[11]. "Migrations are definitely complex processes for which some of the major organizations dealing with their problems, such as UNESCO, the $\mathrm{UN}$, and so on, have chosen definitions and classifications. It can't be unambiguously concluded that they only bring benefits or only harm to societies. They achieve multicultural diversity, innovation, opportunities for development. Numerous programs, strategies, normative documents and frequent debates on the issue of increased 
migration processes in the European Union indicate the seriousness of the problem. The timeliness of the topic suggests that the real effects of immigration in the European Union and the development of new methods and tools to deal with the negative aspects of this process are yet to be clarified"[12]. The current COVID-19 pandemic highlights the importance of strong agencies for managing and mitigating "nontraditional" threats to security in the countries on the all world, as they manifest themselves both of the every countries, and globally. "Given the long-standing civilian versus military resources gap, some observers question whether those agencies that must deal with such challenges are adequately resourced relative to the current and future needs, and whether they are sufficiently integrated into national security plans and operations"[13], this is the one of the main question now in the time of the pandemic COVID-19, because "pandemics are for the most part disease outbreaks that become widespread as a result of the spread of human-to-human infection"[14].

\section{REFERENCES}

[1] Naydenov, Kl., International migration in Europe in the 21 st century, International Scientific Conference GEOBALCANICA, 2018, available to http://geobalcanica.org/wpcontent/uploads/GBP/2018/GBP.2018.22.pdf on 02.02.2021

[2] Naydenov, KL., Modern migration processes ant attitudes of the population in the Republic of Bulgaria- Factors and trends, International Scientific Conference GEOBALCANICA, 2019, available to http://geobalcanica.org/wp-content/uploads/GBP/2019/GBP.2019.50.pdf on 02.02.2021

[3] Ivanov, M., Naydenov, Kl., Migration and demographic challenges for Bulgaria, 5th SGEM International Multidisciplinary Scientific Conferences on SOCIAL SCIENCES and ARTS, 2018, available

https://www.sgemsocial.org/index.php/elibrary?view=publication\&task=show\&id=1191 on 02.02.2021

[4] Ivanov, M., Strategic spatial planning as a factor for development of the regional economy, Contemporary management practices IX, Bulgaria, Burgas, 2016, ISSN: 13138758 , p. $212-218$

[5] Naydenov, Kl., The demographic in the economic development of the Republic of Bulgaria Consequences and decisions, 4th International Multidisciplinary Scientific Conference on Social Sciences and Arts, 2017, available to https://www.sgemsocial.org/index.php/elibrary?view=publication\&task=show\&id=2311 on 02.02.2021

[6] Naydenov, Kl., Influence of the demographic factor on the regional social and economic development, 4th International Multidisciplinary Scientific Conference on Social Sciences and Arts, 2017, available to https://www.sgemsocial.org/index.php/elibrary?view=publication\&task=show\&id=3065 on 02.02.2021

[7] Nikolov, A., Small municipalities near large economic centers are experiencing population growth, available to https://ime.bg/bg/articles/malki-obshtini-krai-golemi-ikonomieski-centroveotbelyazvat-ryst-na-naselenieto/ on 18.04.2021

[8] Naydenov, Kl., Social regional development - trends and perspectives (The Bulgarian case), GEOBALCANICA, 2020, available to http://geobalcanica.org/wpcontent/uploads/GBP/2020/GBP.2020.70.pdf on 18.04.2020

[9] Ivanov, M., Specific features of regional economic security, The power of knowledge, Vol 19, №1, 2017, available to https://ikm.mk/ojs/index.php/KJJ/article/view/3522 on 02.02.2021 
[10] Bailey, D., Clark, J., Colombelli, A., Corradini, C., and other, Regions in a time of pandemic, available to https://www.tandfonline.com/doi/full/10.1080/00343404.2020.1798611 on 02.02.2021

[11] The Future of Migration in the European Union: Future scenarios and tools to stimulate forward-looking discussions, Luxembourg: Publications Office of the European Union, 2018, ISSN 1831-9424, DOI:10.2760/000622

[12] Katsarski, N., Threats and risks to European union security related to migration, International Scientific Conference GEOBALCANICA 2019, available to http://geobalcanica.org/wp-content/uploads/GBP/2019/GBP.2019.43.pdf on 18.04.2021

[13] COVID-19: National Security and Defense Strategy, 2020, available to https://crsreports.congress.gov/product/pdf/IF/IF11525 on 18.04.2021.

[14] Doshi, P., "The elusive definition of pandemic influenza", Bulletin of the World Health Organization, vol. 89 (2011), pp. 532-538.

[15] 265 stories about economics, available to http://www.265obshtini.bg/map/134 on 18.04.2021. 